\title{
IMPLIKASI TERHADAP REALITA PERKEMBANGAN BUSANA ADAT KE PURA BAGI REMAJA HINDU
}

Ni Gusti Ayu Kartika a

Fakultas Dharma Duta

Institut Hindu Dharma Negeri Denpasar

\begin{abstract}
The phenomenon of celebrity appearance which is now hitting Hindus is an empirical reality whose direction of development is not easily rejected, moreover, to avoid. In connection with the phenomenon of the appearance of celebrities of Hindus, it is quite clear that the actions or behavior of the people by making the biological body as a media of aesthetization in the form of celebrity appearances laden with materialist-capitalistconsumerism (objects, money and consumptive style) with the aim of hedonists (enjoying pleasure) mundane). The era of modernization and globalization with its materialist consumerism lifestyle seems to have hypnotized Hindus to submit to all that is modern or posmo, even though it would actually lead to hedonism which only views life to enjoy solitary pleasures. This is the basis of the reduction in the ethics of life, not only in the world now but also in the world of noetic, especially those related to the ethics of religious life and the decreasing level of obedience or obedience to follow ethical norms or rules that must be used as guidelines or guidelines behave.
\end{abstract}

Keywords communication, Tari Abuang, Desa Tenganan, Adat

\section{PENDAHULUAN}

Fenomena berpenampilan selebritis yang kini melanda umat Hindu adalah sebuah realitas empiris yang arah perkembangannya tidak mudah ditolak apalagi hendak mengelak, kecuali memberikan jalan untuk diikuti, tentu saja dengan tetap menjadikan tatanan dan tuntunan etika Hindu sebagai koridor kontrol, agar ke depan dari berpenampilan selebritis, bisa berubah tampil lebih religis atau agamais.

Di satu sisi dalam kesempatan mengikuti upacara persembahyangan, umat memang wajib dan wajar mengekspresikan diri dalam bentuk aneka ragam model penampilan sebagai

\footnotetext{
a gusti_kartika@ihdn.ac.id
} 
refleksi kebebasan, sehingga mereka cenderung mengikuti trend mode yang dalam hal ini menjadikan kalangan selebritis sebagai ikon trend mode. Akan tetapi di lain sisi, ruang dan waktu kesempatan mengikuti upacara persembahyangan di pura yang adalah tempat suci, tidak memberi peluang bagi umat bergaya trendis atau modis dengan penampilan selebritis yang tidak saja mengedepankan segi-segi keindahan (estetis) tetapi juga menonjolkan unsur kemewahan (kapitalis), bahkan erotisme (sensualitas). Sebab sebagaimana dipersyaratkan di dalam etika sembahyang, umat hanya diwajibkan untuk menunjukkan Asuci Laksana, yaitu tampil ke pura dengan badan bersih, busana bersih, rapi dan sopan, disertai pikiran suci, dan hati yang tulus-ikhlas serta tanpa pamrih apapun kecuali hanya untuk tujuan bhakti kehadapan Ida Sang Hyang Widhi, bukan untuk tujuan "pamer diri" melalui keindahan, kemewahan dan sensualitas penampilan selebritisnya.

Jika dibiarkan, berarti mind-set umat ketika hendak atau berada di pura sudah mengalami pergeseran, dari motivasi mencari ketenangan guna mencapai kesadaran berubah kearah mencari kesenangan untuk tujuan bersenang-senang. Memang, senang ke pura untuk dengan sungguh-sungguh ngaturang bakti merupakan sikap atau perilaku umat yang sangat diharapkan. Akan tetapi ketika kesempatan ke Pura hanya dipakai sebagai dalih untuk memanfaatkan aktivitas keagamaan sambil bersenang-senag, antara lain melalui model lain menjadi senang memandangnya, tentu motif ke Pura model begini sudah menyimpang dari tujuan sembahyang itu sendiri.
Apa yang dikemukakan di atas, merupakan sebuah pengamatan atas fenomena yang memang sudah terjadi dan sedang melanda generasi muda Hindu yang secara kasat mata tampak begitu bergairah ke Pura dengan alasan sembahyang, tetapi pada kenyataannya ada "gairah" lain yang menjadi penyemangat untuk berbondongbondong ke Pura yang seakan-akan telah berubah menjadi Pura kawula muda. Boleh jadi fenomena ini antara lain dipengaruhi perkembangan zaman globalisasi yang didorong percepatan oleh kemajuan ilmu pengetahuan dan teknologi serta kecanggihan perangkat komunikasi dan informasi yang tanpa disadari melahirkan gaya hidup posmo yang cenderung bersifat materialistis (mengagungkan kebenaran) dan hedonis (mengutamakan kesenangan duniawi).

Inilah sebuah dinamika yang memfenomena, begitu cepat tumbuh berkembang, menggelayuti orang Bali, yang tanpa disadari telah masuk dalam pusaran arus era posmodern dan globalisasi dengan segala dampak positif dan terbilang juga akses negatif dan destruktifnya. Manifestasinya antara lain, ditunjukkan dengan tampilan yang hampir tidak pernah lepas dari gaya hidup materialistis, kapitalis, konsumeris dan berujung pada gaya hidup hedonis.

\section{PEMBAHASAN}

\section{Muncunya Reduksi Etika}

Adanya kesempatan bagi tereduksinya tatanan dan tuntunan nilainilai, atau norma yang terangkum di dalam etika Hindu yang sesungguhnya menjadi pilar penting dalam memperkuat kerangka bangun sraddha bhakti umat Hindu. Keyakinan agama memberikan kita dorongan untuk berpegang teguh kepada cara hidup dan 
jika mengalami kemerosoan, kepatuhan akan merosot menjadi kebiasaan, dan kebiasaan perlahan-lahan akan lenyap (Radhakrhisnan, 2003: 20).

Kondisi tersebut menurut Nurcholis Madjid dalam Suhanaji (2004: 145) akan dapat menimbulkan krisis dalam masyarakat sebagai akibat begitu cepatnya perubahan atau pergeseran sosial dan individual yang secara simultan hampir tak pernah berhenti berlangsung. Krisi tersebut antara lain dalam bentuk.

Pertama, depresi relatif yaitu perasaan teringkari, tersisihkan atau tertinggal pada orang lain dan kalangan tertentu dalam masyarakat akibat tidak dapat mengikuti perubahan dan kesulitan menyesuaikan diri dengan perubahan. Kedua, dislokasi, yaitu perasan tidak mempunyai tempat dalam tatanana sosial yang sedang berkembang. Ketiga, disorientasi, yaitu perasaan tidak mempunyai pegangan hidup akibat yang ada selama ini tidak dapat dipertahankan karena terasa tidak cocok dan kehilangan identitas. Keempat, negativisme, yaitu perasaan yang mendorong ke arah pandangan yang serba negatif kepada kondisi yang mapan, dengan sikap-sikap tidak percaya, curiga, bermusuhan, melawan dan sebagainya, yang apabila tidak diantisipasi akan dapat menciptakan lahan subur bagi gejala-gejala radikalisme, fanatisme, sekularisme dan lain-lain yang serba negatif.

Isyarat merebaknya kehidupan duniawi tersebut di atas sebenarnya telah disuratkkan di dalam kutipan beberapa sloka kitab Niti Sastra, IV.7 seperti berikut ini;

Singgih yan tekaning yuganta kali tana hana lewiha sakeng mahadhana, tan waktan guna cura pandita widagdha pada mangayap ing dhanecwara, sakwehning rinahasya sang wiku hilang, kula ratu pada hina kasyasih, putradwe pita ninda ring bapa sii cudra banija wara wirya pandita"

Maksudnya :

"sesungguhnya, bila zaman kali (saat ini) datang pada akhir Yuga, maka hanya kekayaan saja yang dihargai. Tidak perlu dikatakan lagi, bahwa orang saleh, orang-orang pandai akan mengabdi kepada orang-orang kaya. Semua pelajaran pendeta yang gaib-gaib diluapakan orang. Keluarga-keluarga yang baik dan raja-raja menjadi hina papa. Anakanak akan menipu dan mengumpat orang tuanya, orang hina dina akan menjadi saudagar, mendapat kemuliaan dan kepandaian" (PGAHN, 1983-1984:29).

Termasuk tentunya menipu diri sendiri dengan dalih ke Pura sembahyang, kenyataannya memanfatkan juga sambil berpacaran atau main judi, dengan prinsip yang penting happy- dapat bersenang-senang, meski dilakukan di area Pura atau di wilayah (mandala) yang masih termasuk ke dalam radius kawasan suci Pura.

Mengubah dan mengendalikan kesadaran umat agar ke pura hanya untuk tujuan sembahyang bukanlah persoalan mudah, tetapi suratan bhagawadgita, XII 7 dan 8 memberikan jalan dan harapan, bahwa :
Tesan aham samuddharta
Mrityu samsara sagarat
Bhawami awesita cetasam;
Mayy ewa mana adhatswa
Mayi buddhim niwesaya
Niwasisyasi mayy ewa
Atu urdhwam samsayah 


\section{Maksudnya :}

“Mereka yang pikirannya tertuju kepada-Ku langsung, O Arjuna, Akulah pembebas mereka dari lautan kesengsaraan atau kematian ; karena itu pusatkan pikiranmu hany pada-Ku kesadaranmu akan ada pada-Ku, dan ini tidak bisa disangsikan lagi" (Pudja, 1981 : 287).

Umat perlu memahami dan menyadari betapa penampilan saja tidak cukup, diperlukan juga usaha untuk melakukan pendalaman rohani dan atau pendakian spiritual agar lebih mencerminkan kesejatian diri sebagai umat Hindu yang berkualitas.

Akan tetapi disadari ataupun tidak, era globalisasi yang begitu cepat memasuki bumi Bali yang sesungguhnya masih pramodern alias tradisional, ternyata telah membawa banyak perubahan, setidaknya dalam hal keterbukaan, dimana orang Bali cenderung begitu mudah menerima unsur-unsur luar (asing) yang masuk, nyaris tanpa seleksi. Sikap permisif atau membiarkan begitu saja apa yang datang, seakan tanpa reserve, membuat orang Bali dalam hal ini umat Hindu begitu rentan terpengaruh, terutama oleh hal-hal yang bersifat negatif, destruktif dan kontraproduktif terhadap keajegan masa depan Bali, termasuk ajeg agama Hindu dengan segala tatanan nilai-nilai luhurnya.

Gejalanya dapat dicermati, mulai dari orientasi hidup yang sudah bergerak ke arah materi dan tampilan, dan tidak lagi mengedepankan rohani dan pendalaman. Sikap mengagungkan kebebasan berekspresi, ditambah dengan sifat dan karakter individualistik yang rata-rata dimiliki setiap orang (Bali), serta cara berfikir yang mulai modern dengan memandang segala sesuatu itu secara pragmatis, semata-mata untuk kepentingan praktis dan ekonomis, menjadikan eksistensi orang Bali yang notabene adalah pemeluk Hindu, seperti berada pada dunia global.

Realita ini dikemukakan juga oleh Sudibya (1994 : 9) dengan menyatakan bahwa, "masyarakat dewasa ini secara jujur harus diakui telah mengalami pergeseran penilaian. Dimana tingkat penghargaan sebagian masyarakat terhadap individu lebih didasarkan pada "apa yang dimiliki" dan "apa yang dikonsumsi". Dalam kerangka berpikir Erich Fromm, itulah yang disebut konsep to have, bagaimana bisa "memiliki atau megkonsumsi" lebih banyak, bukan to be, sebagaimana konsep agama yang selalu mendorong umatnya agar "menjadi" orang yang lebih berkualitas dan bermakna. Sepertinya penampilan telah mengalahkan pendalaman, bahwa umat Hindu ngaturang bhakti ke Pura, sesungguhnya bukan konteks "teologi"; refleksi kedalam keyakinan (sraddha) yang dilandasi ketulusan dan kesucian hati yang tanpa pamrih, melainkan disemangati oleh "ideologi pasar", yang menonjol tampilan artifisial (bauatan) dan finansial (kemampuan keuangan) serta diwarnai nuansa keramaian, kesemarakan atau kegairahan, seperti halnya arena pasar (Widana, 2009 : 10)

Ini sebuah fenomena yang sudah menjadi realita sosial yang teramat sulit untuk disembunyikan. Sebab era modernisasi dan globalisasi dengan gaya hidup konsumerisme materialisnya seakan telah menghipnotis umat Hindu untuk tunduk mengikuti dan melakoni semua yang serba bergaya modern atau posmo itu, meskipun sebenarnya akan menjerumuskan ke arah hedonisme yang 
hanya memandang hidup ini untuk menikmati kesenangan semata. Dari sinilah pangkal terjadinya reduksi terhadap etika kehidupan, tidak saja di dunia sekala tetapi juga di dunia niskala, terutama yang berhubungan dengan etika hidup berkeagamaan.

Umat Hindu sebagai bagian dari anggota masyarakat akan terus bergerak lebih jauh ke arah krisis legitimasi (moral) sebagaimana dijelaskan Hebermas (2004) bahwa masyarakat tidak (akan) lagi mendengarkan imbauan-imbauan moral pihak berwenang, atau seperti kata Kristeva (dalam Piliang, 2003 : 274) yang menyebutkan kondisi ini dengan istilah abjeksi (abjection), yakni suatu kondisi dimana yang paling rendah. Moralitas berada pada dasar yang paling rendahh ketika batas-batas moral dan etika itu sudah lenyap (baik-buruk, benar-salah). Inilah yang kemudian dapat disebut sebagai titik nadir keruntuhan moralitas dalam bentuk ketidakpatuhan atau ketidaktaatan umat terhadap tatanan dan tuntunan etika Hindu yang sudah seharusnya selalu menjadi landasan dalam berperilaku, termasuk dalam berpenampilan. Sebab jika tidak demikian, manusia (umat) akan dengan mudah berpandangan bahwa seseorang itu boleh melakukan apa saja, asalkan tidak mengganggu orang lain. Untuk itu, orang secara mudah bisa mencopot nilai-nilai etika atau moral apa saja yang tidak cocok bagi dirinya (Robinson dan Garratt, 2004). Bahkan dengan mengacu kepada Hardiman (2003 : 109), keadaan demikian yang berkembang dewasa ini disebutkan sebagai zaman edan yang agaknya analog dengan anomie masyarakat dalam kosakata Durkheim atau alienasi individu dalam kosakata Marx, bukan dipandang dalam perspektif ke depan, melainkan ke belakang atau bukan sebagai kemajuan yang berkedamaian, melainkan mundur dengan kekacauan sehingga orang Bali (umat Hindu) menyebutkan dengan istilah zaman nungkalik atau zaman kaliyuga, zaman yang diigambarkan dengan konndisi dharma (kebenaran) dikuasai adharma (kejahatan).

Perihal zaman kaliyuga yang banyak ditandai dengan kondisi dan atau perilaku manusia "ngedan" dan serba "terbalik" dan atau nungkalik ini, secara tersurat dan tersirat dengan jelas digambarkan, diisyaratkan, bahkan sekaligus diingatkan melalui petikan sloka di dalam kitab Niti Sastra, IV.10 dan 11 seperti berikut ini :

"pangdening kali murkaning jana wimoha matukar

arebut kawiryan, tan wring ratnya makol lawan bhratara

wandhawa, ripu kinayuh pakacrayan, dewa-drewya

winacadharma rinurah kabuyutan inilan pada sepi, wyarta

ng capatha su-pracasti linebur tekaping adhama murka ringg

jagatt ; Wwang mahyun ri kawehaning dana daridra, krepana dumadak dhanecwara. Wwang duratmaka dirgha-jiwita,

sirang sujana dumadak alpakamreta, Wwang duccila sucila,

durnaya wiweka, kujana sujanawibhagana, Sang

rajasiwiteng susena ta ya, sang madum-amilih ulah wiparyaya"

Maksudnya :

"Karena pengaruh zaman Kali, manusia menjadi kegila-gilaan, suka berkelahi, berebut kedudukan yang tinggi-tinggi. Mereka tidak mengenal dunianya sendiri, bergumul melawan saudara-saudaranya dan 
mencari perlindungan kepada musuh. Barang-barang suci dirusak, tempat-tempat suci dimusnahkan, dan orang dilarang masuk ke tempat suci, sehingga tempat menjadi sepi. Kutuk tak berarti lagi, hak istimewa tidak berlaku, semua itu karena perbuatan orang-orang angkara murka ; orang-orang yang suka memberi sedekah jatuh miskin, orang yang kikir jadi kaya raya. Penjahat-penjahat panjang umurnya, akan tetapi orang-orang baik lekas mati. Tingkah laku hina dianggap utama, dan kebodohan dinamakan kebijaksanaan, orangorang yang rendah budinya disebut mulia, sungguh suatu anggapan yang aneh. Raja menurut kepada materimeterinya, dan orang kaya yang harus mengurus segalanya bertindak salah" (PGAHN, 1983-1984:3031).

Menanggapi situasi zaman kaliedan ini, Raditya (2009 : 6) memberi pandangan, bahwa :

"di zaman posmodernis yang liberal seperti sekarang ini, agama cenderung dijadikan status sosial yang sifatnya simbolis semata. Tak sedikit masyarakat kekinian yang mulai enggan membawa ajaran agama ketika dihadapkan kepada persoalan hasrat dan libidonya. Misalnya, mereka tidak ingin dicap binal dan mengumbar aurat ketika berpakaian transparan atau berpacaran bahkan berciuman di depan publik. Apa yang mereka lakukan itu hanyalah dianggap sebagai gaya hidup dan mengikuti tren alias gaul".

Begitupun mind-set umat Hindu kekinian yang juga tak lepas dari gaya penampilan ngetren. Dalam konteks tteori fenomenologis, gejala mengikuti trend mode adalah sejalan dengan apa yang dikemukakan Berger (dalam Kumbara, 2008: 2) bahwa dengan bertitik tolak dari manusia, berarti manusia itu adalah sebagai aktor-aktor yang mempunyai peran sangat besar dalam pembentukan kebudayaan.

Fenomena penampilan selebritis umat Hindu, bukanlah sebagai suatu gejala yang harus dipelajari tentang 'siapa' yang melakukannya, tetapi lebih kepada penelusuran tentang 'bagaimana' dan 'mengapa' hal itu bisa terjadi. Dalam konteks ini, teori interaksionisme simbolik yang dikemukakan Blumer (dalam Eizer, 2003 : 319) melalui ringkasannya mengemukakan beberapa prinsip dasar yaitu bahwa : 1) tidak seperti binatang, manusia dibekali kemampuan untuk berpikir, 2) kemampuan berpikir dibentuk oleh interaksi sosial, 3) dalam interaksi sosial, manusia mempelajari makna dan simbol yang memungkinkan mereka menggunakan kemampuan berpikir mereka yang khusus itu, dan 4) makna dan simbol memungkinkan manusia melakukan tindakan khusus dan berinteraksi.

Ritzer (2002 : 52) lebih jauh mengulas, bahwa terkait dengan tindakan atau perilaku seseorang, dihubungkan kemudian dengan penampilan selebritis umat Hindu, tampaknya dapat dipahami, fenomena tersebut tidaklah dibuat secara langsung terhadap tindakan tersebut, melainkan didasarkan atas "makna" yang diberikan terhadap perilaku itu. Interaksi antar individu (dalam pergaulan), diantarai oleh penggunaan simbol-simbol, interpretasi atau dengan saling berusaha untuk saling memahami maksud dari tindakan atau perilaku dimaksud.

Khusus tentang ideologi posmo itu sendiri sepertinya telah 
mendekonstruksi tatanan mapan dalam strata dan struktur sosial, termasuk bentuk-bentuk interaksi sosial untuk lebih 'cair' (larut) dalam ideologi global yang seakan tanpa sekat, dan begitu cepat berakselerasi menembus batasbatas dunia, termasuk menembus sekatsekat sakral religi dengan segala bentuk, simbol dan maknanya, yang terkadang dalam realitas empirik menjadi tidak sistemik dan justru bergerak menjadi bias atau ambigu (membingungkan). Mana yang harus tetap diipertahankan dalam kemapanan konstruk (konsep atau gagasan), dan apa yang harus diikuti sekarang serta bagaimana memformulasikan antara kemapanan konsep dengan keikutsertaan dalam konteks kekinian (posmo) yang selalu berorientasi pada trend posmodernitas.

Sebagai sebuah fenomena, penampilan selebritis umat Hindu, dengan mengacu pada pandangan Sartre (dalam Hassan http: atau atau pdskjijaya.com), dikatakan bahwa "berbagai pemahaman ataau penghayatan kita tentang penampilan seseorang erat kaitannya dengan eksitensi yang manunggal dengan kebutuhan. Segala yang menggejala melalui tubuh kita tidak mungkin diperlakukan sebagai kenyataan objektif belaka dan dipisahkan dari penghayatan kita sebagai keseluruhan subjektif. Sebab, objektivitas penampilan tubuh, juga merepresentasikan kenyataan subjektif yang tersembunyi ke dalam bentuk simbol.

Makna berpenampilan yang semula menyimbolkan arti kepatuhan pada tatanan etis, kini bergerak menjadi lebih bebas mencari atau mengambil bentuk yang merefleksikan kebebasan berimprovisasi dengan memodifikasi tubuh anatomis menjadi tubuh selebritis. Sehingga kata Sartre (dalam Hassan http: atau atau pdskjijaya.com), "peragaan manusia bukanlah sekedar penampilannya sebagai badan yang objektif. Melalui kalimat analog Sartre menyatakan : "Saya tidak menyambut uluran tangan seseorang menjabat sebuah tangan belaka, tanpa menyadari bahwa saya sambut seseorang dan jabatan tangan itu disertai oleh penghayatan subjektif masing-masing".

Bagi Blumer (dalam Soeprato, 2002 : 121) teori interaksionisme simboliknya ini merujuk pada karakter interaksi khusus yang berlangsung antar manusia. Manusia sebagai aktor, tidak semata-mata beraksi (bertindak atau berperilaku) terhadap tindakan lain, tetapi dia menafsirkan dan mendefinisikan setiap tindakan orang lain. Respon aktor secara langsung maupun tidak, selalu didasarkan atas penilaian makna tersebut. Oleh karena itu, interaksi manusia dijembatani oleh penggunaan simbol-simbol penafsiran atau dengan menemukan makna tindakan orang lain.

Karena itu, dengan berdasarkan atas premis dasar teori interaksionisme simbolik, Blumer (dalam Soetomo, 2008 : 124) menegaskan bahwa ada tiga terminologi kunci dalam memahami kehidupan sosial, termasuk fenomena berpenampilan selebritis, yaitu konsep individu, adanya interaksi dan dilakukannya interprestasi. Bahwa interaksionisme simbolik beranggapan dan menilai bahwa perilaku manusia semata-mata merupakan tanggapan terhadap rangsangan dari luar dirinya. Dalam hal fenomena penampilan selebritis umat Hindu, tentu yang dimaksudkan adalah pengaruh rangsangan yang berasal dari luar umat itu sendiri dalam bentuk perkembangan 
trend mode yang seakan mengepung dan tak kuasa menolak apalagi hendak mengelak.

Untuk membaca simpul itu, maka makna di balik simbol-simbol itu akan dapat ditanggap, disingkap dan kemudian diungkap. Jadi, hakekat simbol adalah bukan semata-mata terletak pada apa yang tampak dalam bentuk materi yang berwujud, seperti halnya dalam berpenampilan selebritis, tetapi lebih kepada apa yang "berada" (tersembunyi) di balik perwujudan itu sendiri.

Kedua, pada kenyataannya, secara badaniah manusia dengan tekstur lekak lekuk tubuh anatominya, adalah makhluk seni (estetis), yang secara alamiah memang sudah menjadi bagian dari keindahan yang kemudian oleh umat Hindu di era posmo, dieksplorasi dan dieksploitasi dengan gaya selebritis.

Ketiga, sebagai bagian dari gaya hidup posmo, dimana apapun yang melekat, dipakai dan atau ditampilkan umat Hindu kekinian, selalu bisa diasosiasikan sebagai kedudukan atau status sosial ekonominya dengan maksud menggambarkan tentang "siapa" dan "bagaimana" diri seseorang tersebut.

Sementara itu dari segi implikasinya, fenomena penampilan selebritis memunculkan tiga kondisi yaitu : sekularisasi, suatu bentuk profanisasi terhadap aktivitas religi menjadi lebih duniawi, yang dari padanya berakibat pada lahirnya sikap ambigu (mendua) dengan mencampur adukkan batasan-batasn suci (sakral) dengan yang tidak suci (profan). Keadaan itu menjadi pendorong bagi lahirnya alienasi, dimana umat seakan-akan kehilangan dorongan hati, kehilangan spiritualitas dan kehilangan kontrol terhadap kemanusiaan untuk membawa seseorang menjadi berjati jati diri atau berkepribadian agamais.

Implikasi lebih lanjut, dari keadaan alienasi, muncul pula situasi anomie, dimana umat Hindu seakanakan hidup tanpa norma, aturan ataupun bimbingan, bahkan merasa terjungkir dan kehilangan pegangan. Sehingga terjadilah apa yang disebut sebagai reduksi etika dalam bentuk ketidakpatuhan lagi terhadap kaidah etika atau ajaran agama Hindu yang sepetutnya dipedomani.

\section{Munculnya Ambiquitas dan Alienasi Anomie}

Ambiquitas atau "kemenduaan" adalah sebuah "kesadaran yang keliru', "ketidaksadaran". Di satu sisi umat sadat (ingat) ke Pura menunaikan kewajiban agama, tetapi di lain sisi sekaligus juga menjadi "tidak sadar" (tidak tahu) bahwa pada kenyataannya umat telah mencampuradukkan kegiatan religi yang sebenarnya bertujuan mencari atau mencapai ketenangan, diganti dengan aktivitas bersenang-senang. Ke Pura dengan rasa senang atau bersukacita tentu amat baik dilakukan sebagai refleksi kegairahan beragama. Akan tetapi menjadi hal sebaliknya jika ke/di Pura dimanfaatkan juga untuk kesempatan mencari kesenangan atau sekedar bersenang-senang, dan hal itu jelas bukan sesuatu yang menyenangkan.

Kemudian Alienasi, adalah suatu keadaan "merasa sepi", terasing dari orang lain, terisolasi dari kawankawannya dan bisa juga memusuhi orang lain. Jadi alienasi berarti kehilangan dorongan hati untuk bergaul (motif egoisme, atomisasi), kehilanggan kreativitas (motif menonton, kerutinan), dan kehilangan otonomi (motif 
pasivisme), kehilangan otonomi (motif pemujaan komoditi yang memasuki semua orang) dan singkatnya, menghancurkan "potensi kemanusiaan" (Sztiompka, 2004 : 91).

Dengan demikian keadaan alienasi dapat membawa seseorang menjado tanpa jati diri atau kepribadian, yang tidak saja dapat terjadi ketika berkesinambungan dengan bidang pekerjaan, tetapi juga dapat urusan lain seperti persaingan politik, kultur, pendidikan, kesenian, kesenangan, konsumsi, keluarga dan bidang lainnya. Gambaran suram, tentang masyarakat modern atau posmo yang terjerat alienasi mencapai puncaknya dalam karya Eric Fromm (1966:1976) yang melukiskannya sebagai "masyarakat gila" dan Herbert Marcuse (1964) yang menganggap masyarakat modern atau posmo sebagai "proyek gagal", jalan buntu sejarah manusia.

Selanjutnya Anomie, menurut Durkheim, sifat alami manusia adalah buas, egoistis, individualistis yang siap bertempur tanpa menghiraukan kepentingan orang lain. Hanya jika manusia dikekang oleh aturan kultural, norma dan nilai, perang semua melawan semua dapat dihindarkan dari kehidupan sosial yang selaras mungkin dapat terwujud. Namun ada keadaan historis ketika aturan kultural, termasuk tentunya aturan agama, kehilangan daya mengikatnya atau hancur sama sekali. Keadaan itulah yang disebut anomie atau tanpa norma.

Agama yang merangkum keseluruhan nilai-nilai etika atau normanorma kehidupan, masih dan harus tetap dipandang sebagai tempat legitimasi sekaligus menjadi media yang dapat memulihkan atau menguatkan tatanan etika atau moral dari kerunntuhannya.
Karena itu, sikap atau perilaku anomie yang merasa seolah-olah hidup tanpa nilai, norma atau aturan tidak dapat dibiarkan berlanjut.

Hanya saja persoalannya, di zaman dimana pendidikan atau pembinaan agama kepada umat begitu kurang, malah nyaris tidak ada sama sekali, baik di lingkungan keluarga maupun di masyarakat, ditambah dengan gempuran arus modernisasi dengan gelombang globalisasinya yang membawa kemajuan di bidang teknologi komunikasi dan informasi yang demikian canggih, bukan hal aneh apabila apa yang diharapkan oleh ajaran agama termasuk para orang tua yang begitu ideal, seringkali terpental oleh kenyataan tentang betapa kondisi pergaulan umat kita sekarang.

Keadaan-keadaan seperti terurai di atas itulah yang menjadikan masyarakat atau umat seolah-olah berada dalam keadaan mendua (ambigu), terasing (alienasi) dan seakanakan tanpa nilai, ketiadaan norma atau kehilangan pegangan (anomie) yang tentu saja jika dibiarkan akan dapat menjerumuskan umat kepada tata cara atau gaya hidup masa kini yangg cenderung bebas, sekuler dan hedonis.

Mencemati dinamika dan fenomena di atas, Durkeim dalam Suhanaji (2004:146), memandangnya sebagai proses transpormasi dari masyarakat tradisional ke masyarakat industri di era postmodern yang tentunya dapat menimbulkan masalah sosial tersendiri. la menggambarkan hal itu sebagai pergeseran dari bentuk solidaritas mekanis (atas dasar kebersamaan) 


\section{Kesimpulan dan Saran \\ Kesimpulan}

Atas beberapa simpulan di atas, sebagai wujud apresiasi dan atensi terhadap penampilan selebritis umat Hindu, sekaligus sebagai bentuk antisipasi terhadap kian berkembangnya gejala berpenampilan yang semakin menjauh dari kaidah etis, maka beberapa saran yang disampaikan adalah, agar setiap umat Hindu jika melakukan kegiatan keagamaan, khususnya etika mengikuti upacara persembahyangan di Pura, hendaknya berpenampilan sesuai dengan ajaran etika atau kesusilaan Hindu yang disebut Asuci Laksana; Jika saat berada di Pura, membawa perangkat teknologi komunikasi seperti Handphone (HP), terutama ketika persembahyangan berlangsung agar tidak menghidupkan atau melakukan hubungan telepon; Hendaknya Hindu dalam kesempatan melakukan aktivitas keagamaan, lebih mementingkan kedalaman bhakti daripada sekedar mempertontonkan gaya berpenampilan.

\section{Saran}

Sejalan dengan usahaa untuk terus meningkatkan sradha bhakti umat, maka beberapa rekomendasi patut diajukan kepada, Lembaga Parisada Hindu Dharma Indonesia, sebagai mejelis tertinggi umat Hindu, kiranya ini dapat dijadikan bahan masukan untuk kemudian menjadi pertimbangan bagi kemungkinan pembuatan atau penyusunan suatu rancangan aturan berkenaan dengan tata krama atau etika berpenampilan; Kepada institusi masyarakat, mulai dari tingkatan keluarga, banjar dengan seke terunanya, Desa Pakraman, termasuk lembaga sekolah dan terutama lagi bagi umat Hindu pada umumnya, agar turut berperan serta dalam mensosialisasikan dan sekaligus mempraktekkan aturan norma berdasarkan etika Hindu, bahwa dalam berpenampilan hendaknya umat Hindu tetap berpegangan pad kaidah etika, tidak sekedar mengikuti trend mode sesuai selera dalam bergaya.

\section{DAFTAR PUSTAKA}

Adlin, Alfathri (Ed). 2006. Registrasi Gaya Hidup : Teori Dan Realitas. Yogyakarta \& Bandung. Jalasutra.

Anderson, Perry. 2004. Asal Usul Post Modernitas (Terjemahan). Jogjakarta : Insight Reference

Ardika, I Wayan., I Wayan Pastika, I Nyoman Suarka, I Wayan Srijaya (Ed). 2008. Dinamika Sosial Masayarakat Bali Dalam Lintasan Sejarah. Denpasar : Tanpa Penerbit.

Ardianto, E dan Lokiati Komala Erdinaya. 2007. Komunikasi Massa : Suatu Pengantar. Bandung : Remaja Rosdakarya.

Agung, A.A.. Ayu Ketut. 2004. Busana Adat Bali. Denpasar. Pustaka Bali Post.

Barnard, Malcolm. 2006. Fashion Sebagai Komunikasi : Cara Mengkomunikasikan Identitas Sosial, Seksual, Kelas, dan Gender. Yogyakarta : Jalasutra.

Cavallaro, Dani. 2004 Critical and Cultural Theory, Teori Kritis Dan Teori Budaya. (Penerjemah : Laily Rahmawati). Yogyakarta. Niagara. 
Chaney, David. 2008. Lifestyles : Sebuah Pengantar Komprehensif. (Penerjemah:Nuraeni). Yogyakarta Jalasutra.

Dister Ofm, Nico Syukur. 1988. Pengalaman dan Motivasi Beragama. Yogyakarta : Kanisius. 